\title{
Near-Infrared Fluorescence Imaging in Patients Undergoing Pancreaticoduodenectomy
}

\author{
M. Hutteman ${ }^{\text {a }} \quad$ J.R. van der Vorst ${ }^{\text {a }} \quad$ J.S.D. Mieog ${ }^{\text {a }}$ B.A. Bonsing ${ }^{a}$ \\ H.H. Hartgrink ${ }^{a}$ P.J.K. Kuppen ${ }^{a} \quad$ C.W.G.M. Löwik ${ }^{b} \quad$ J.V. Frangioni ${ }^{c}$ \\ C.J.H. van de Velde ${ }^{a} \quad$ A.L. Vahrmeijer ${ }^{a}$ \\ Departments of a Surgery and ${ }^{b}$ Endocrinology, Leiden University Medical Center, Leiden, The Netherlands; \\ 'Departments of Medicine and Radiology, Beth Israel Deaconess Medical Center, Boston, Mass., USA
}

\section{Key Words}

Bile duct imaging $\cdot$ Bile duct reconstruction • Image-guided surgery $\cdot$ Indocyanine green ·

Near-infrared fluorescence imaging $\cdot$ Pancreatic surgery

\begin{abstract}
Background: Intraoperative visualization of pancreatic tumors has the potential to improve radical resection rates. Intraoperative visualization of the common bile duct and bile duct anastomoses could be of added value. In this study, we explored the use of indocyanine green (ICG) for these applications and attempted to optimize injection timing and dose. Methods: Eight patients undergoing a pancreaticoduodenectomy were injected intravenously with 5 or $10 \mathrm{mg}$ ICG. During and after injection, the pancreas, tumor, common bile duct and surrounding organs were imaged in real time using the Mini-FLARETM near-infrared (NIR) imaging system. Results: No clear tumor-to-pancreas contrast was observed, except for incidental contrast in 1 patient. The common bile duct was clearly visualized using NIR fluorescence, within 10 min after injection, with a maximal contrast between 30 and 90 min after injection. Patency of biliary anastomoses could be visualized due to biliary excretion of ICG.
\end{abstract}

Conclusion: No useful tumor demarcation could be visualized in pancreatic cancer patients after intravenous injection of ICG. However, the common bile duct and biliary anastomoses were clearly visualized during the observation period. Therefore, these imaging strategies could be beneficial during biliary surgery in cases where the surgical anatomy is aberrant or difficult to identify.

Copyright $\odot 2011$ S. Karger AG, Basel

\section{Introduction}

Pancreatic cancer is the fourth leading cause of cancer-related mortality in the United States, with an incidence of approximately 38,000 cases and an estimated 34,000 deaths. The overall 5-year survival rate is very low $(<5 \%)$ [1]. Approximately $10-15 \%$ of patients are eligible for surgical resection, which is presently the only potentially curative treatment option. Even after curative resection, the reported 5-year survival rates are disappoint-

M.H. and J.R.v.d.V. contributed equally to the study and share first authorship.

\section{KARGER}

() 2011 S. Karger AG, Basel

Fax +41613061234

E-Mail karger@karger.ch

www.karger.com 
ing and vary from 10 to $17 \%$ [2-5]. Several factors, such as tumor size, lymph node status, tumor grade and blood vessel invasion, are correlated with prognosis. Involvement of tumor margins is an important prognostic factor, as reported survival for R0 (radical) resections (20.3 months) is twice that of $\mathrm{R} 1$ resections (10.3 months) [6]. For preoperative staging and determination of resectability, the imaging procedure of choice is a multiphase, multidetector helical computed tomography with intravenous administration of a contrast agent combined with an endoscopic ultrasonography [7]

During pancreatic surgery, assessment of the extent of the pancreatic tumor is made based on visual inspection and palpation, sometimes in conjunction with intraoperative ultrasonography $[8,9]$. Intraoperative tumor identification remains challenging, partly because the surrounding pancreatic tissue is frequently inflamed. Local recurrence rates of $72-86 \%$ are reported [10-12], which in part could be caused by inadequate intraoperative evaluation of the location and extent of the tumor.

Near-infrared (NIR) fluorescence imaging is a promising technique to facilitate intraoperative, real-time, visual information [13-15]. In order to detect tumors using NIR fluorescence, contrast agents that target tumor-specific characteristics can be used to selectively label tumor cells [16-19]. Novel NIR fluorescent agents have been developed that target tumor-specific cell surface markers $[16,20]$, enzymatic activity $[17,19,21]$ or increased glucose metabolism [22]. However, these tumor-specific agents are not yet available for clinical use. The only NIR fluorescent contrast agents currently available, methylene blue and indocyanine green (ICG), are not tumor specific. However, the enhanced permeability and retention (EPR) effect can potentially be used to obtain accumulation of non-targeted contrast agents in tumors [23, 24]. Due to newly formed, more porous blood vessels, molecules can passively accumulate in the surrounding tissue. Furthermore, poorly developed lymphatics in the tumor result in an increased retention. Previous studies showed breast carcinomas and liver tumors could be identified noninvasively with NIR fluorescence using ICG based on the EPR effect [25-28]. The aim of our study was to assess the applicability of NIR fluorescence imaging using ICG to provide a clear tumor-to-background contrast in oncologic pancreatic surgery.

Because ICG is almost exclusively excreted into the bile, it can also be used for intraoperative NIR fluorescence exploration of the biliary anatomy [29-31]. This can be useful in patients with a difficult laparoscopic cholecystectomy, due to an aberrant biliary anatomy or an acute cholecystitis, for example. Furthermore, ICG can potentially be used to assess anastomosis patency in patients undergoing bile duct reconstruction. This is a wellsuited setting to study both biliary anatomy and anastomosis patency intraoperatively, as the common bile duct can be visualized for a long time during pancreaticoduodenectomy.

\section{Materials and Methods}

Intraoperative NIR Imaging System (Mini-FLARE ${ }^{T M}$ )

Intraoperative imaging was performed using the hand-held Fluorescence-Assisted Resection and Exploration (Mini-FLARE) image-guided surgery system as described by Mieog et al. [manuscript accepted for publication]. This system consists of two wavelength-isolated light sources: a 'white' light source, generating 26,600 lx of 400-650 $\mathrm{nm}$ light and an NIR light source, generating $7.7 \mathrm{~mW} / \mathrm{cm}^{2}$ of $760 \mathrm{~nm}$ light. Color video and NIR fluorescence images are simultaneously acquired and displayed in real time using custom optics and software that separate the color video and NIR fluorescence images. A pseudo-colored (lime green) merged image of the color video and NIR fluorescence images is also displayed. The imaging head is attached to a flexible gooseneck arm, which permits positioning of the imaging head virtually anywhere over the surgical field, even at extreme angles. For intraoperative use, the imaging head and imaging system pole stand are wrapped in a sterile shield and drape (Medical Technique Inc., Tucson, Ariz., USA).

\section{ICG Preparation and Administration}

ICG (25-mg vials) was purchased from Pulsion Medical Systems (Munich, Germany) and resuspended in $10 \mathrm{ml}$ of sterile water for injection to yield a $2.5 \mathrm{mg} / \mathrm{ml}(3.2 \mathrm{~mm})$ stock solution. Of this stock solution 2 or $4 \mathrm{ml}$, corresponding to doses of 5 or $10 \mathrm{mg}$, were administered.

\section{Clinical Trial}

The study was approved by the local Medical Ethics Committee of the Leiden University Medical Center and was performed in accordance with the ethical standards of the Helsinki Declaration of 1975. A total of 8 consecutive patients with suspected ampullary or pancreatic head carcinoma planned to undergo curative resection were included. All patients provided informed consent. Exclusion criteria included pregnancy, lactation or an allergy to iodine, shellfish or ICG. The surgical technique used in our center implies a standard pancreaticoduodenectomy with resection of peripancreatic tissues and lymph nodes. Following resection, reconstruction is performed with pancreaticojejunostomy, choledochojejunostomy and pylorojejunostomy for pyloruspreserving pancreaticoduodenectomy or a gastrojejunostomy as part of Whipple's procedure. After opening the omental bursa, performing the Kocher maneuver and exploration of the hepatoduodenal ligament, the pancreatic tumor was fully exposed. The Mini-FLARE imaging system was positioned $30 \mathrm{~cm}$ above the surgical field. Next, 4 patients were intravenously administered $5 \mathrm{mg}$ ICG diluted in $2 \mathrm{ml}$ of sterile water as a bolus and 4 patients received $10 \mathrm{mg}$ ICG diluted in $4 \mathrm{ml}$ of sterile water as an intrave- 
Table 1. Patient characteristics

\begin{tabular}{|c|c|c|c|c|c|c|c|c|c|c|c|c|c|c|c|c|c|c|c|}
\hline $\mathrm{Pt}$ & $\begin{array}{l}\text { Age } \\
\text { years }\end{array}$ & Sex & $\begin{array}{l}\text { Weight } \\
\mathrm{kg}\end{array}$ & $\begin{array}{l}\mathrm{t} \text { Height } \\
\mathrm{cm}\end{array}$ & BMI & $\begin{array}{l}\mathrm{AP} \\
\mathrm{U} / \mathrm{l}\end{array}$ & $\begin{array}{l}\text { GGT } \\
\mathrm{U} / 1\end{array}$ & $\begin{array}{l}\text { ASAT } \\
\text { U/l }\end{array}$ & $\begin{array}{l}\text { ALAT } \\
\text { U/l }\end{array}$ & $\begin{array}{l}\text { Tumor } \\
\text { size, } \mathrm{cm}\end{array}$ & $\begin{array}{l}\text { Tumor } \\
\text { location }\end{array}$ & Surgery & $\mathrm{T}$ & $\mathrm{N}$ & M & $\mathrm{R}$ & $\begin{array}{l}\text { Vasc. } \\
\text { inv. }\end{array}$ & $\begin{array}{l}\text { Perin. } \\
\text { inv. }\end{array}$ & Pathology \\
\hline 1 & 39 & $\mathrm{M}$ & 90 & 186 & 26 & 261 & 86 & 92 & 155 & N/A & head & bypa & 3 & + & - & N/A & N/A & N/A & poorly diff. AC \\
\hline 2 & 76 & $\mathrm{~F}$ & 64 & 164 & 24 & 97 & 72 & 21 & 16 & 4.7 & ampulla & Whipple & 3 & - & - & R0 & - & + & poorly diff. AC \\
\hline 3 & 45 & M & 65 & 179 & 20 & 118 & 274 & 20 & 19 & 4 & head & PPPD & 3 & + & - & R1 & - & + & well-diff. AC \\
\hline 4 & 32 & M & 88 & 188 & 25 & 114 & 66 & 48 & 78 & - & - & Whipple & & - & - & & & & no malignancy \\
\hline 5 & 74 & $\mathrm{~F}$ & 75 & 169 & 26 & 72 & 46 & 69 & 40 & 6 & head & Whipple & 2 & + & - & R1 & - & _- & $\mathrm{AC}$ \\
\hline 6 & 61 & $\mathrm{~F}$ & 73 & 176 & 24 & 674 & 1,472 & 280 & 292 & 1.7 & head & PPPD & 3 & + & _ & R0 & _- & + & $\mathrm{AC}$ \\
\hline 7 & 46 & $\mathrm{~F}$ & 89 & 170 & 31 & 42 & 11 & 59 & 39 & 1.8 & head & Whipple & 1 & + & - & $\mathrm{R} 1$ & - & - & neuroendocrine \\
\hline 8 & 62 & M & 68 & 180 & 21 & 71 & 64 & 21 & 23 & 2.3 & duodenum & PPPD & & - & - & R0 & - & - & adenomatous polyp \\
\hline
\end{tabular}

$\mathrm{AC}=$ Adenocarcinoma; $\mathrm{AP}=$ alkaline phosphatase ALAT = alanine aminotransferase; $\mathrm{ASAT}=$ aspartate aminotransferase $\mathrm{BMI}=\mathrm{body}$ mass index; diff. $=$ differentiated; GGT $=\boldsymbol{\gamma}$-glutamyltransferase; N/A $=$ not available due to unresectable tumor; Perin. inv. $=$ perineural invasion; $P P P D=$ pyloruspreserving pancreaticoduodenectomy; $\mathrm{Pt}=$ patient; Vasc. inv. = vascular invasion.

nous bolus. All operating room lights, with the exception of the white light and NIR light of the Mini-FLARE imaging system, were dimmed. The NIR fluorescence measurements of the pancreatic tumor, pancreas, duodenum, stomach, liver, gall bladder and common bile duct were recorded at the time of injection ( $\mathrm{T}=$ 0 ), and $45 \mathrm{~s}$ and $3,10,30,60,90,120$ and 180 min after injection. At each measurement, camera exposure times were set appropriately to prevent the NIR fluorescence signal from reaching saturation. Bile duct imaging ended at 90 min because the bile duct was resected at this time as part of the pancreaticoduodenectomy. Furthermore, imaging of the choledochojejunostomy was performed to assess leakage and patency. Fluorescent intensity of these structures was quantified using the custom MiniFLARE software. To calculate tumor-to-pancreas ratios, tumor and healthy pancreas regions of interest were manually drawn, guided by palpation. Signal-to-background ratios (SBRs) for the common bile duct were manually drawn, and a background region of interest was drawn on directly surrounding tissue.

\section{Statistical Analysis}

For statistical analysis and graph design, GraphPad Prism Software (version 5.01; GraphPad Software, La Jolla, Calif., USA) and SPSS (version 17.0; SPSS, Chicago, Ill., USA) were used. All data were reported as means \pm SD or medians and ranges. To compare the SBRs between the two concentration groups, $t$ tests were used. Repeated-measures ANOVAs were used to test differences between time points. All statistical tests were two tailed and $\mathrm{p}<0.05$ was considered significant.

\section{Results}

Patient and tumor characteristics are listed in table 1. Eight patients undergoing surgery for a suspected ampullary or pancreatic head carcinoma were included in the study. In 1 patient, the common bile duct was cut several minutes after ICG administration and therefore measurements $>3$ min were excluded from the analysis. Four patients underwent a complete Whipple procedure, 3 patients underwent a pylorus-preserving pancreaticoduodenectomy, and 1 patient had an unresectable tumor, resulting in a biopsy without further resection.

\section{Tumor Imaging}

Directly after injection, superficial arterial flow of ICG was identified by NIR fluorescence on the surface of the pancreas followed by venous drainage. In the 5-mg patient group $(n=4)$, a mean tumor-to-pancreas ratio of $0.89 \pm 0.25$ was observed. In the 10 -mg patient group $(\mathrm{n}=4)$, a mean tumor-to-pancreas ratio of $1.22 \pm 0.39$ was observed (fig. 1a). Time had no significant effect on the tumor-to-pancreas ratio $(\mathrm{p}=0.899)$. Tumor-to-pancreas ratios were significantly higher in the 10 -mg group compared to the $5-\mathrm{mg}$ group $(\mathrm{p}=0.002)$. In 1 patient (patient 5, 10-mg dose group), a clear NIR fluorescent hotspot was observed on the pancreas (fig. 1b). Histological analyses confirmed that the signal corresponded to tumor tissue surrounding the pancreatic duct. Other than this incidental finding, no contrast was observed.

\section{Imaging of the Common Bile Duct Using NIR \\ Fluorescence}

Within 10 min after administration of ICG, the common bile duct, cystic duct and common hepatic duct could clearly be identified by NIR fluorescence (fig. 2a, b) in all patients. The NIR fluorescence signal of the liver outshone the left and right hepatic ducts and therefore prevented clear visualization. The fluorescent signal of the bile ducts lasted until 90 min after injection, at which point the bile duct was resected, along with the head of the pancreas and the duodenum, as part of the pancreaticoduodenectomy. No difference was observed between 
Fig. 1. Tumor-to-pancreas contrast using NIR fluorescence and ICG: tumor-to-pancreas ratios (means $\pm \mathrm{SD}$ ) of the pancreatic tumors over time, per dose group (a). b Color video (left panel), NIR fluorescence (middle panel) and a color-NIR overlay (right panel) of intraoperative imaging of the pancreas. In this example, clear contrast (arrow) is shown between pancreatic tumor and normal pancreatic tissue (P) 20 min after administration of $10 \mathrm{mg}$ of ICG. However, this was an incidental finding in 1 patient. $\mathrm{D}=$ Duodenum.

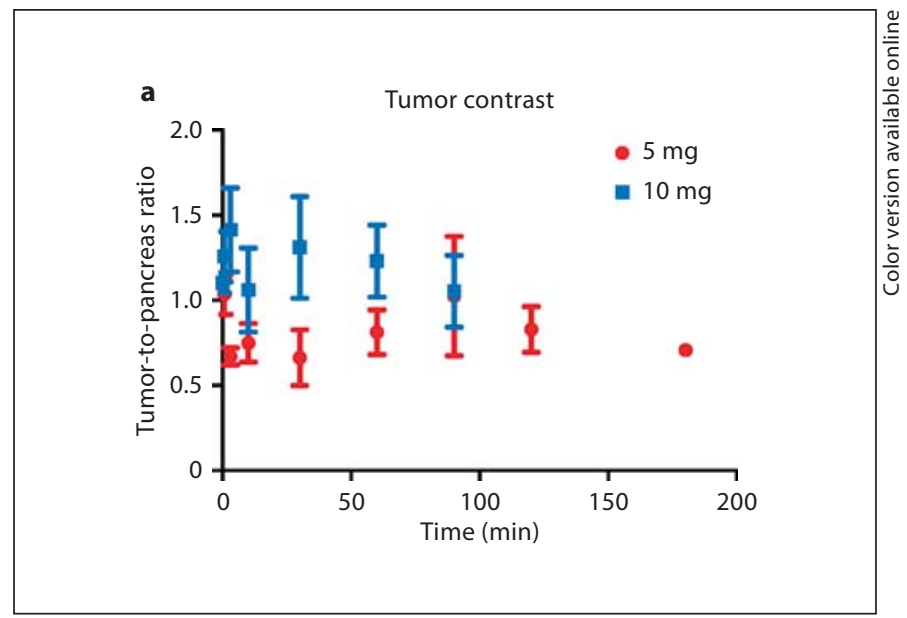

b
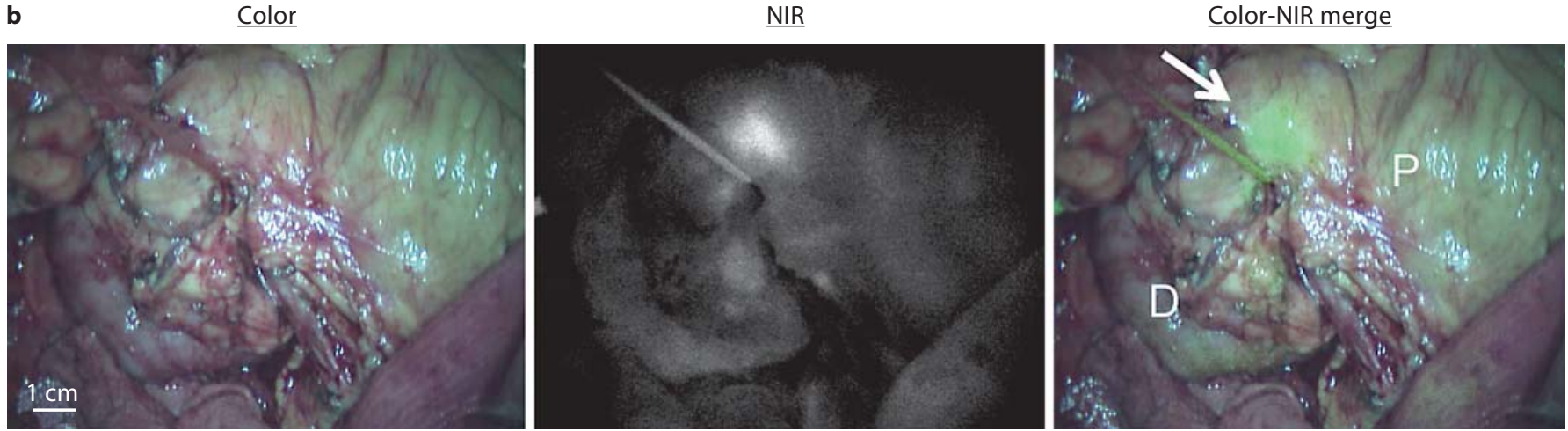

the 5- and 10-mg groups $(\mathrm{p}=0.849)$. Time significantly influenced SBR $(p=0.002)$. An optimum was found between 30 and 90 min after injection, with a maximum mean SBR of $6.24 \pm 1.32$ at $60 \mathrm{~min}$ after injection. After completion of the choledochojejunostomy, anastomotic patency could be confirmed by visualizing the NIR fluorescence signal passing the anastomosis into the jejunum (fig. 2c).

\section{Biodistribution of ICG}

The NIR fluorescence signal of the pancreas, stomach, liver, duodenum and common bile duct was measured at fixed time intervals (fig. 3). As reported in preclinical studies [30], within the first 2 min a vascular signal (an arterial phase followed by a venous phase) could be visualized. The pancreas, stomach and duodenum showed comparable washout patterns. As ICG is cleared by the liver, the liver and common bile duct exhibited high levels of NIR fluorescence, indicating hepatic uptake and clearance in bile.

Pancreatic Cancer and Bile Duct Imaging

\section{Discussion}

The first objective of this study was to exploit the EPR effect $[23,24]$ to induce retention of the non-targeted probe ICG in pancreatic tumors. However, in all but 1 patient, no useful intraoperative tumor-to-pancreas ratios in pancreatic cancer patients were noted using NIR fluorescence and ICG. In 1 patient, a clear hotspot was observed on the pancreas, which corresponded with the resected adenocarcinoma. No pathological characteristics were observed that could account for this phenomenon. Several factors might explain the observed lack of contrast in all other patients. Healthy pancreas tissue showed a relatively high uptake of ICG, whereas tumor tissue showed similar uptake. As washout of the NIR fluorescence signal was comparable in both healthy pancreas tissue and tumor tissue, no EPR effect could be visualized. This is possibly the result of different tumor biology of pancreatic cancer when compared to breast cancer, in which the EPR effect has been observed in pre-

Eur Surg Res 2011;47:90-97 
Fig. 2. Intraoperative imaging of the common bile duct using NIR fluorescence and ICG: SBRs (means \pm SD) of the common bile duct over time, per dose group (a). SBRs for the common bile duct were calculated. A background region-of-interest was drawn on directly surrounding tissue. b Color video (left panel), NIR fluorescence (middle panel) and a color-NIR overlay (right panel) of intraoperative imaging of the common bile duct in a patient who underwent a cholecystectomy during previous surgery $30 \mathrm{~min}$ after administration of $5 \mathrm{mg}$ of ICG. A clear contrast is shown between the common bile duct (arrow) and surrounding tissue. c Color video (left panel), NIR fluorescence (middle panel) and a color-NIR overlay (right panel) of a choledochojejunostomy (arrow) $30 \mathrm{~min}$ after completion of the anastomosis. NIR fluorescence signal of excreted ICG is visualized intraluminally in the jejunum, indicating anastomotic patency and absence of leakage.

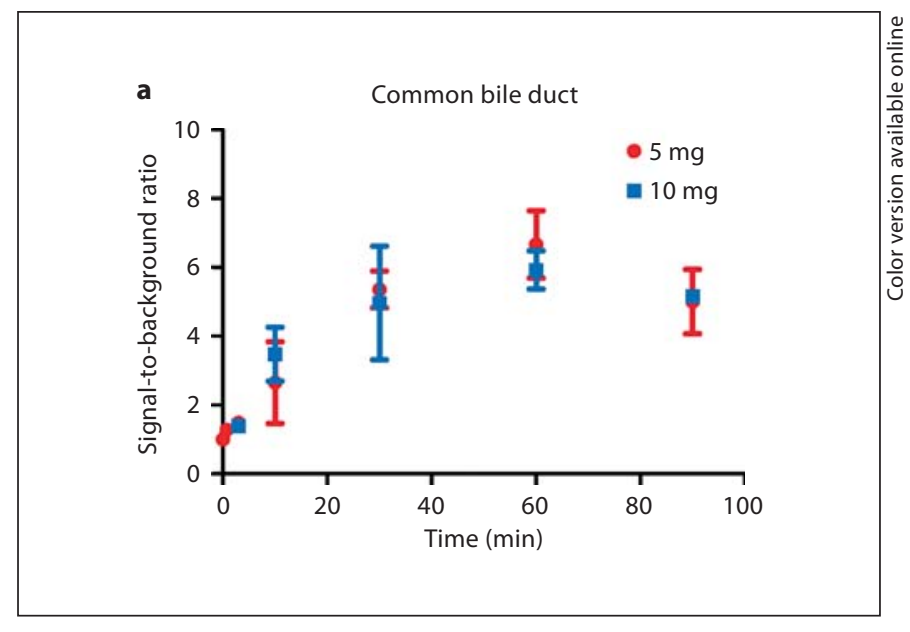

b

Color

$\underline{N I R}$
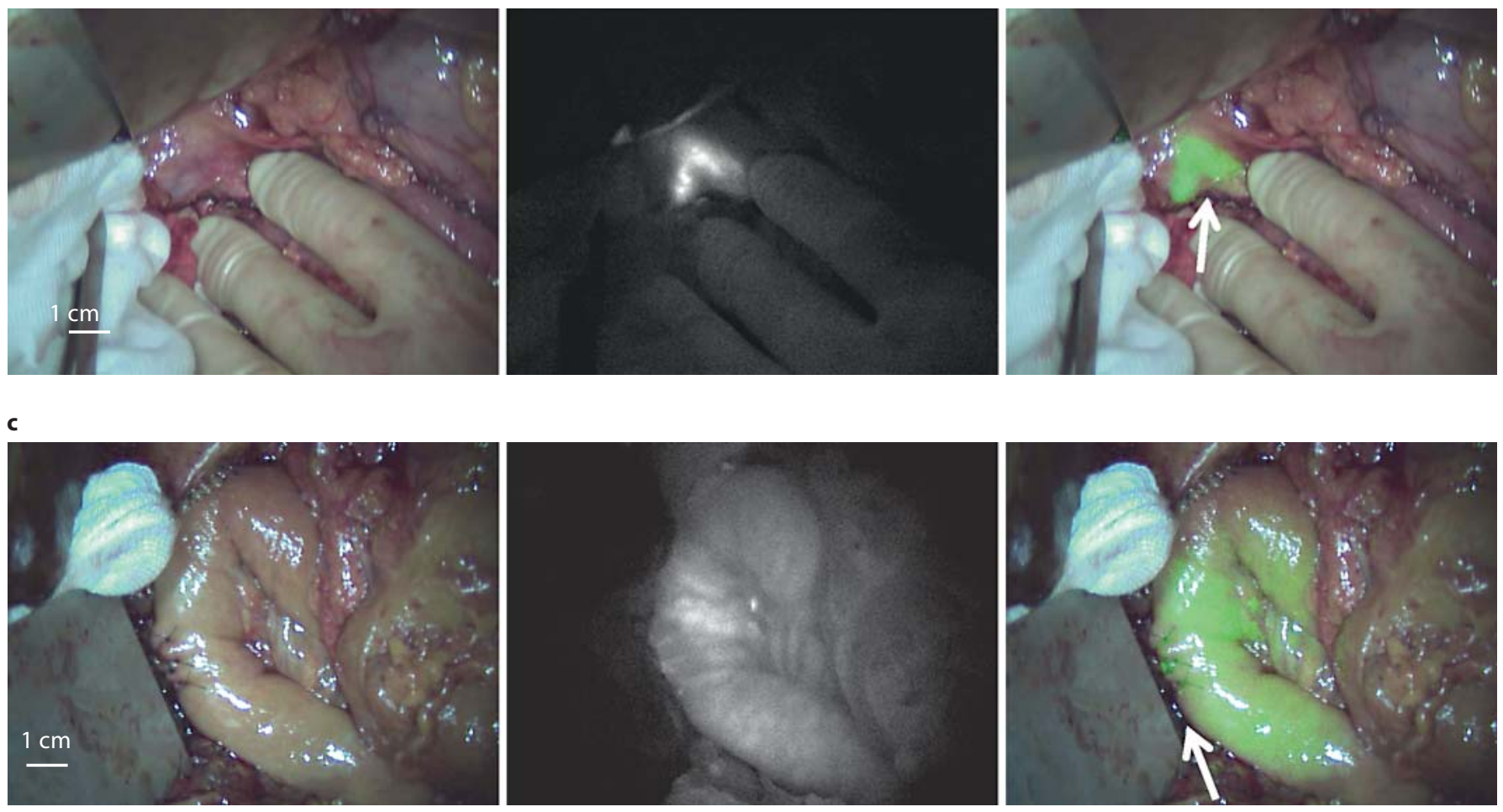

vious studies. Several earlier studies reported a lower perfusion of tumor tissue in comparison with healthy pancreas tissue $[32,33]$, which might decrease availability of ICG for a potential EPR effect of the tumor. Furthermore, previous studies that reported an EPR effect of ICG in breast tumors used detection methods (laser scanning or optical tomography) that may detect lower concentrations of ICG but require post-processing, and are therefore not applicable for real-time intraoperative imaging $[26,27]$.

Novel NIR fluorescent probes are being developed to increase signal penetration depth and decrease background uptake. For multiple applications within cancer surgery, it is imperative to design improved tumor targeting probes. Tumor targeting can be accomplished by conjugating a fluorophore to a targeting ligand such as anti- 


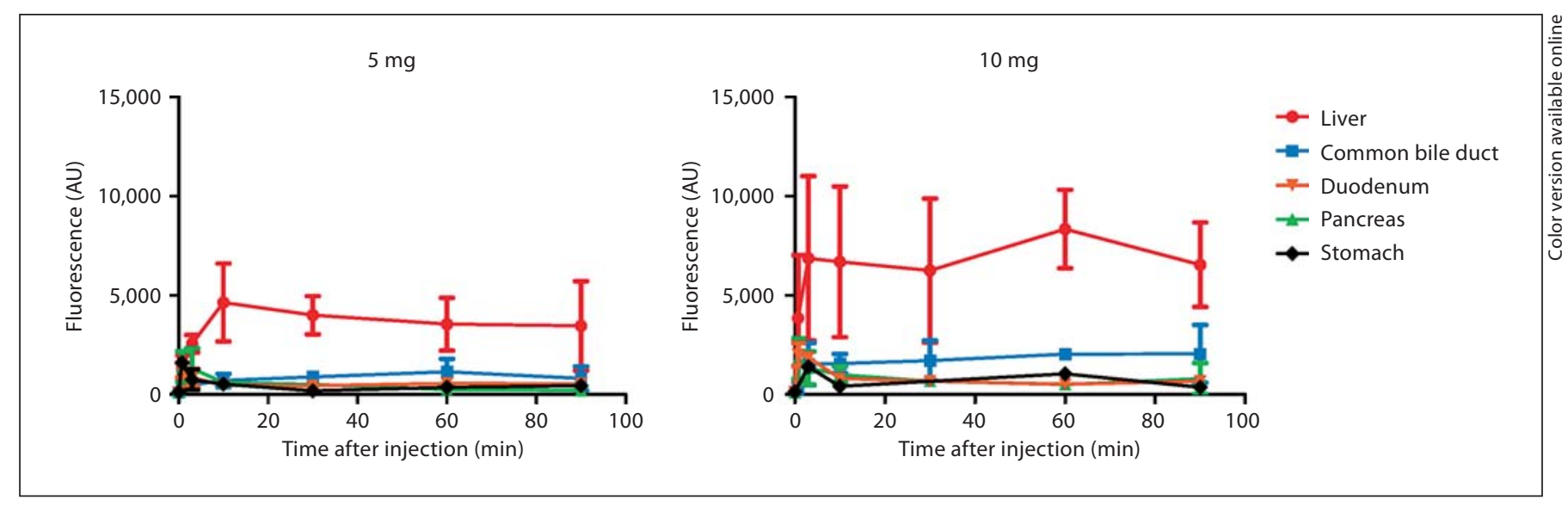

Fig. 3. Biodistribution of ICG in organs exposed during pancreaticoduodenectomy: shown are NIR fluorescence intensities of organs exposed during pancreaticoduodenectomy. Measurements of the duodenum were taken over an area not containing bile. Intensities are shown over time for both 5-mg (left panel) and 10-mg (right panel) groups.

bodies or peptides, for example [16, 19, 21, 22]. It is expected that several of those tumor-targeted probes will be available for first-in-human trials within the coming years.

The second objective of this study was to evaluate the biodistribution of ICG and its clearance by the liver into the bile. Patients undergoing a pancreaticoduodenectomy are well suited for this study, as the bile ducts and abdominal organs can be studied for a relatively long time. As stated before, iatrogenic common bile duct injury occurs in patients undergoing cholecystectomy. A non-invasive imaging modality that can visualize the common bile duct intraoperatively could potentially reduce the incidence of common bile duct injury in these patients. For example, this technique can help the surgeon identify vital structures during difficult laparoscopic cholecystectomies in patients with acute cholecystitis or aberrant biliary anatomy. This technique could potentially prevent the need to convert to an open procedure.

In this study, the common bile duct was identified using NIR fluorescence imaging after ICG administration in all patients. This is in concordance with preclinical data described by Matsui et al. [30] and clinical studies of patients undergoing cholecystectomy $[29,31]$. A useful contrast between the common bile duct and surrounding tissue was observed $\geq 10$ min after injection. The optimal timing of ICG administration prior to imaging lies between 30 and $90 \mathrm{~min}$. In this interval, mean SBRs of 5-6 were observed. Ideally, background fluorescence levels of all surrounding organs should be minimal. In this study, the liver signal remained high throughout the imaging interval. Although this did not prevent a contrast being observed between common bile duct and surrounding tissue, future studies should focus on optimal timing to minimize background fluorescence, especially when studying the liver. Indeed, in a separate study, in which patients with colorectal liver metastases were injected intravenously with $10 \mathrm{mg}$ ICG $24 \mathrm{~h}$ prior to liver surgery, liver fluorescence decreased to background levels, while bile duct imaging was still possible. However, compared to the fluorescent intensity observed in the present study, the bile duct signal was significantly decreased by $88 \%$ [van der Vorst et al., manuscript in preparation]. Therefore, novel NIR fluorescent agents should be developed that are excreted into bile, with minimal liver uptake, thereby reducing background fluorescence and increasing the ability to visualize bile ducts. In contrast to most other imaging systems, the Mini-FLARE imaging system used in this study can display the NIR fluorescence signal in relation to the surgical anatomy, by simultaneously displaying color video and NIR fluorescence. This feature is of added benefit in performing true image-guided surgery. The Mini-FLARE can only be used during open surgery. However, most cholecystectomies are performed by laparoscopy. In order to enable intraoperative NIR fluorescence imaging during laparoscopic surgery, laparoscopic camera systems are currently being developed and tested [30, 31, 34]. Furthermore, as with all novel techniques, large clinical studies are necessary to prove the added value of NIR fluorescence imaging in patients un- 
dergoing a cholecystectomy. These trials can use the data presented in this study to select the optimal time of imaging after ICG administration.

This study showed that no useful tumor demarcation could be visualized in pancreatic cancer patients using intraoperative NIR fluorescence imaging after ICG administration. Furthermore, our study showed the ability to visualize the common bile duct after ICG administration and demonstrated the influence of time on SBR. Moreover, patency of the jejunal-biliary anastomosis could be visualized. For a translation to clinical practice, larger trials should be executed. This is dependent on broad availability of commercial intraoperative NIR fluorescence imaging systems. When these imaging systems become available for use in the clinic in the coming years, the true value of this technique can be assessed.

\section{Acknowledgments}

We thank Lindsey Gendall for editing. This work was supported in part by the Nuts Ohra Fund, the Foundation Maurits and Anna de Kock, and NIH grant No. R01-CA-115296.

\section{Disclosure Statement}

The authors declare that they have no conflict of interest. All FLARE technology is owned by the Beth Israel Deaconess Medical Center, a teaching hospital of Harvard Medical School. As inventor, Dr. Frangioni may some day receive royalties if products are commercialized. Dr. Frangioni is the founder and unpaid director of the FLARE Foundation, a non-profit organization focused on promoting the dissemination of medical imaging technology for research and clinical use.

\section{References}

1 Jemal A, Siegel R, Ward E, Hao Y, Xu J, Murray T, Thun MJ: Cancer statistics, 2008. CA Cancer J Clin 2008;58:71-96.

$\checkmark 2$ Yeo CJ, Sohn TA, Cameron JL, Hruban RH, Lillemoe KD, Pitt HA: Periampullary adenocarcinoma: analysis of 5-year survivors. Ann Surg 1998;227:821-831.

- 3 Sohn TA, Yeo CJ, Cameron JL, Koniaris L, Kaushal S, Abrams RA, Sauter PK, Coleman J, Hruban RH, Lillemoe KD: Resected adenocarcinoma of the pancreas-616 patients: results, outcomes, and prognostic indicators. J Gastrointest Surg 2000;4:567-579.

-4 Cleary SP, Gryfe R, Guindi M, Greig P, Smith L, Mackenzie R, Strasberg S, Hanna S, Taylor B, Langer B, Gallinger S: Prognostic factors in resected pancreatic adenocarcinoma: analysis of actual 5-year survivors. J Am Coll Surg 2004;198:722-731.

$\checkmark 5$ Conlon KC, Klimstra DS, Brennan MF: Long-term survival after curative resection for pancreatic ductal adenocarcinoma. Clinicopathologic analysis of 5-year survivors. Ann Surg 1996;223:273-279.

-6 Garcea G, Dennison AR, Pattenden CJ, Neal CP, Sutton CD, Berry DP: Survival following curative resection for pancreatic ductal adenocarcinoma. A systematic review of the literature. JOP 2008;9:99-132.

-7 Miura F, Takada T, Amano H, Yoshida M, Furui S, Takeshita K: Diagnosis of pancreatic cancer. HPB (Oxford) 2006;8:337-342.

-8 Shin LK, Brant-Zawadzki G, Kamaya A, Jeffrey RB: Intraoperative ultrasound of the pancreas. Ultrasound Q 2009;25:39-48.

\S Sun MR, Brennan DD, Kruskal JB, Kane RA: Intraoperative ultrasonography of the pancreas. Radiographics 2010;30:1935-1953.
10 Griffin JF, Smalley SR, Jewell W, Paradelo JC, Reymond RD, Hassanein RE, Evans RG: Patterns of failure after curative resection of pancreatic carcinoma. Cancer 1990;66:5661.

11 Sperti C, Pasquali C, Piccoli A, Pedrazzoli S: Recurrence after resection for ductal adenocarcinoma of the pancreas. World J Surg 1997;21:195-200.

$\checkmark 12$ Westerdahl J, Andren-Sandberg A, Ihse I: Recurrence of exocrine pancreatic cancer local or hepatic? Hepatogastroenterology 1993;40:384-387.

$\checkmark 13$ Keereweer S, Kerrebijn JD, van Driel PB, Xie B, Kaijzel EL, Snoeks TJ, Que I, Hutteman M, van der Vorst JR, Mieog JS, Vahrmeijer AL, van de Velde CJ, Baatenburg de Jong RJ, Lowik CW: Optical image-guided surgery where do we stand? Mol Imaging Biol 2011; 13:199-207.

14 Frangioni JV: New technologies for human cancer imaging. J Clin Oncol 2008;26:40124021.

$\checkmark 15$ Gioux S, Choi HS, Frangioni JV: Imageguided surgery using invisible near-infrared light: fundamentals of clinical translation. Mol Imaging 2010;9:237-255.

$\checkmark 16$ Lee SB, Hassan M, Fisher R, Chertov O, Chernomordik V, Kramer-Marek G, Gandjbakhche A, Capala J: Affibody molecules for in vivo characterization of HER2-positive tumors by near-infrared imaging. Clin Cancer Res 2008;14:3840-3849.

17 Jiang T, Olson ES, Nguyen QT, Roy M, Jennings PA, Tsien RY: Tumor imaging by means of proteolytic activation of cell-penetrating peptides. Proc Natl Acad Sci USA 2004;101:17867-17872.
18 Hutteman M, Mieog JS, van der Vorst JR, Dijkstra J, Kuppen PJ, van der Laan AM, Tanke HJ, Kaijzel EL, Que I, van de Velde CJ, Lowik CW, Vahrmeijer AL: Intraoperative near-infrared fluorescence imaging of colorectal metastases targeting integrin $\alpha(v) \beta(3)$ expression in a syngeneic rat model. Eur J Surg Oncol 2011;37:252-257.

19 Mieog JS, Hutteman M, van der Vorst JR, Kuppen PJ, Que I, Dijkstra J, Kaijzel EL, Prins F, Lowik CW, Smit VT, van de Velde CJ, Vahrmeijer AL: Image-guided tumor resection using real-time near-infrared fluorescence in a syngeneic rat model of primary breast cancer. Breast Cancer Res Treat 2010, E-pub ahead of print.

20 Gleysteen JP, Newman JR, Chhieng D, Frost A, Zinn KR, Rosenthal EL: Fluorescent labeled anti-EGFR antibody for identification of regional and distant metastasis in a preclinical xenograft model. Head Neck 2008; 30:782-789.

21 Weissleder R, Tung CH, Mahmood U, Bogdanov A Jr: In vivo imaging of tumors with protease-activated near-infrared fluorescent probes. Nat Biotechnol 1999;17:375-378.

-22 Zhou H, Luby-Phelps K, Mickey BE, Habib AA, Mason RP, Zhao D: Dynamic near-infrared optical imaging of 2-deoxyglucose uptake by intracranial glioma of athymic mice. PLoS One 2009;4:e8051.

23 Matsumura Y, Maeda H: A new concept for macromolecular therapeutics in cancer chemotherapy: mechanism of tumoritropic accumulation of proteins and the antitumor agent smancs. Cancer Res 1986;46:63876392. 
24 Maeda H, Wu J, Sawa T, Matsumura Y, Hori $\mathrm{K}$ : Tumor vascular permeability and the EPR effect in macromolecular therapeutics: a review. J Control Release 2000;65:271-284.

-25 Hagen A, Grosenick D, Macdonald R, Rinneberg H, Burock S, Warnick P, Poellinger A, Schlag PM: Late-fluorescence mammography assesses tumor capillary permeability and differentiates malignant from benign lesions. Opt Express 2009;17:17016-17033.

-26 Intes X, Ripoll J, Chen Y, Nioka S, Yodh AG, Chance B: In vivo continuous-wave optical breast imaging enhanced with indocyanine green. Med Phys 2003;30:1039-1047.

-27 Alacam B, Yazici B, Intes X, Nioka S, Chance B: Pharmacokinetic-rate images of indocyanine green for breast tumors using near-infrared optical methods. Phys Med Biol 2008; 53:837-859.
28 Ishizawa T, Fukushima N, Shibahara J, Masuda K, Tamura S, Aoki T, Hasegawa K, Beck Y, Fukayama M, Kokudo N: Real-time identification of liver cancers by using indocyanine green fluorescent imaging. Cancer 2009;115:2491-2504.

29 Tagaya N, Shimoda M, Kato M, Nakagawa A, Abe A, Iwasaki Y, Oishi H, Shirotani N, Kubota K: Intraoperative exploration of biliary anatomy using fluorescence imaging of indocyanine green in experimental and clinical cholecystectomies. J Hepatobiliary Pancreat Surg 2009;17:595-600.

30 Matsui A, Tanaka E, Choi HS, Winer JH, Kianzad V, Gioux S, Laurence RG, Frangioni JV: Real-time intra-operative near-infrared fluorescence identification of the extrahepatic bile ducts using clinically available contrast agents. Surgery 2010;148:87-95.

-31 Ishizawa T, Bandai Y, Ijichi M, Kaneko J, Hasegawa K, Kokudo N: Fluorescent cholangiography illuminating the biliary tree during laparoscopic cholecystectomy. Br J Surg 2010;97:1369-1377.
2 Reuter SR, Redman HC, Bookstein JJ: Differential problems in the angiographic diagnosis of carcinoma of the pancreas. Radiology 1970;96:93-99.

-33 Komar G, Kauhanen S, Liukko K, Seppanen M, Kajander S, Ovaska J, Nuutila P, Minn H: Decreased blood flow with increased metabolic activity: a novel sign of pancreatic tumor aggressiveness. Clin Cancer Res 2009; 15:5511-5517.

34 Aoki T, Murakami M, Yasuda D, Shimizu Y, Kusano T, Matsuda K, Niiya T, Kato H, Murai N, Otsuka K, Kusano M, Kato T: Intraoperative fluorescent imaging using indocyanine green for liver mapping and cholangiography. J Hepatobiliary Pancreat Surg 2009; 17:590-594. 